\title{
RANCANG BANGUN UNIVERSAL CYLINDRICAL GRINDING ATTACHMENT SISTEM MODUL PADA MESIN BUBUT MANUAL
}

\author{
Sutopo $^{1}$, Paryanto ${ }^{2}$, Aan Ardian ${ }^{3}$, Arif Marwanto ${ }^{4}$ \\ 1,2,3,4 Jurusan Pendidikan Teknik Mesin FT UNY \\ Email: sutopo@uny.ac.id
}

\begin{abstract}
The purpose of this research is to design and to analyze the feasibility of universal cylindrical grinding attachment that can be attached to conventional lathes. The research is a quantitative research using ADDIE Reseach and Development $(R \& D)$ procedure. Data were collected using observation, by means of questionnaire and documentation. Data were analyzed using quantitative-descriptive technique. Results are: (1) the universal cylindrical grinding attachment design is a modified hand-grinding machine with added components to add internal cylindrical grinding functionality; (2) all aspects are in the category of "strongly agree", so it can be concluded that the design is feasible to use.
\end{abstract}

Keywords: design, universal cylindrical grinding attachment, research and development, ADDIE model

\begin{abstract}
ABSTRAK
Tujuan penelitian ini adalah untuk merancang mesin universal cylindrical grinding attachment yang dapat dipasang dan digunakan pada mesin bubut konvensional serta untuk mengetahui kelayakannya. Penelitian ini menggunakan pendekatan penelitian kuantitatif dengan prosedur penelitian Pengembangan/Reseach and Development (R\&D) model ADDIE. Pengumpulan data menggunakan teknik observasi dan alat pengumpul data menggunakan angket dan dokumentasi. Analisis data menggunakan teknik deskriptif kuantitatif. Hasil penelitian ini adalah: (1) Rancangan mesin universal cylindrical grinding attachment pada mesin bubut manual dibuat dengan memodifikasi mesin gerinda tangan dengan dengan menambahkan beberapa komponen, yaitu: tapper shaft, clamping nuts, slive, shank, nut, bottom holder, dan top holder, sehingga fungsinya bertambah yaitu mampu digunakan untuk menggerinda internal silindris.; (2) rentang penilaian rerata keseluruhan aspek termasuk dalam kategori sangat setuju, sehingga dapat disimpulkan bahwa mesin ini layak untuk digunakan.
\end{abstract}

Kata kunci: rancang bangun, universal cylindrical grinding attachment, ADDIE model

\section{PENDAHULUAN}

Fakultas Teknik UNY sebagai lembaga pendidikan tinggi yang bergerak di bidang Pendidikan Teknologi Kejuruan, terus berupaya meningkatkan efektivitas dan efisiensi keberhasilan pendidikan, baik keberhasilan internal maupun keberhasilan eksternal dari pendidikan yang dilaksanakan. Keberhasilan internal sistem pendidikan dapat terakumulasi dalam kuantitas dan kualitas (mutu) hasil pendidikan, yakni kemampuan lulusan (output). Bekal kemampuan lulusan adalah memiliki kompetensi atau kapasitas kemampuan dalam bersikap, berpengetahuan, dan berketerampilan profesional kependidikan, yang seluruhnya menunjukkan perubahan tingkah laku lulusan dan terindikasi pada tingkat prestasi hasil belajar pendidikan atau yudisium-nya. Keberhasilan internal pendidikan lulusan, tidak terlepas dari hasil sistem pendidikannya. Dalam sistem pendidikan meliputi interaksi dari berbagai elemen, diantaranya unsur raw input peserta didik dan unsur-unsur proses pendidikan. Proses pendidikan yang sistematis harus simultan dan terorganisasi dalam interaksi dan sinergik dari unsur pengelola, program atau kurikulum, operasi pelaksanaan dalam pencapaian visi dan misi, serta orientasi pencapaian tujuannya. 
Keberhasilan eksternal pendidikan dapat ditunjukan oleh keberhasilan lulusan dalam memperoleh pekerjaan, yang tergambarkan dalam keadaan pencarian pekerjaan ketika setelah lulus, penempatan pekerjaan yang sesuai, dan kinerja lulusan menurut persepsi lembaga tempat lulusan bekerja. Lapangan kerja untuk lulusan FT UNY antara lain bekerja di lembaga kependidikan dengan tugas pokok mengajar sebagai pendidik atau guru, bekerja di lembaga non kependidikan seperti di industri, atau lulusan dapat bekerja sebagai wiraswasta. Keseimbangan antara keberhasilan internal dan eksternal pendidikan, sangat tergantung pada optimalisasi peranan lembaga pendidikan dalam hal ini Fakultas Teknik Universitas Negeri Yogyakarta.

Kaitannya dengan hal di atas, Jurusan Pendidikan Teknik Mesin (PT Mesin) selalu berusaha meningkatkan kualitas dan relevansi lulusan dengan kebutuhan dunia kerja, salah satunya melalui upaya perbaikan dan pengembangan kurikulum. Perbaikan kurikulum ini semakin relevan dengan diberlakukannya Undang-undang Nomor 20 Tahun 2003 tentang Sistem Pendidikan Nasional, Peraturan pemerintah Nomor 19 tahun 2005 tentang Standar Nasional Pendidikan, Undang-undang Nomor 14 Tahun 2005 tentang Guru dan Dosen, serta penerapan kurikulum 2013. Tuntutan kompetensi guru yang makin tinggi dan diwujudkan melalui proses sertifikasi harus sedini mungkin diantisipasi oleh Lembaga Pendidik Tenaga Kependidikan (LPTK). Sebagai pencetak tenaga kependidikan di bidang teknologi dan kejuruan yang nantinya akan mengajar di sekolah menengah kejuruan (SMK), maka perbaikan kurikulum yang dilakukan harus disesuaikan dengan kurikulum yang diberlakukan di SMK.

Pada saat ini untuk bidang keahlian Teknologi dan Rekayasa khususnya untuk program keahlian Teknik Mesin, paket keahlian yang ada terdiri dari teknik gambar manufaktur, teknik pemesinan bubut, teknik pemesinan frais, teknik pemesinan gerinda dan teknik pemesinan CNC (SK Dirjen Dikdasmen No. 130 tahun 2017). Sehingga sudah selayaknya mata kuliah yang dilaksanakan di Jurusan PT Mesin mengacu pada paket keahlian yang ada di SMK tersebut. Selama ini dari kelima paket keahlian tersebut untuk teknik pemesinan gerinda belum dapat dilaksanakan dengan baik, karena baru satu semester ini dijalankan sebagai mata kuliah praktik yang wajib ditempuh oleh mahasiswa. Karena merupakan mata kuliah baru, tentunya perlu didukung dengan adanya fasilitas sumber belajar berupa mesin gerinda beserta peralatannya.

Saat ini mesin gerinda yang dimiliki jurusan PT Mesin adalah 1 unit mesin gerinda silindris luar, 1 unit mesin gerinda datar, dan 2 unit mesin gerinda tool, dimana beberapa mesin tersebut kondisinya sudah tidak baik, sehingga sangat kurang menunjang proses perkuliahan. Dan dari segi kuantitas, jumlah mesin gerinda yang ada tersebut dirasakan sangat kurang, bila digunakan oleh rata-rata satu kelas praktik sejumlah 20 mahasiswa. Kondisi ini memaksa tim pemesinan dalam menyusun job praktik sebagai materi perkuliahan pemesinan gerinda, harus memodifikasi dengan kemapuan lain seperti membubut dan frais, sehingga job gerinda yang ada saat ini terkesan malah lebih dominan pada proses pembentukan blank dengan menggunakan proses bubut dan frais, sehingga dalam perkuliahan ini belum mampu memaksimalkan pemberian kompetensi menggerinda.

Upaya agar kompetensi yang diharapkan dalam mata kuliah pemesinan gerinda ini dapat dikuasai secara keseluruhan, maka diperlukan sebuah alat atau mesin gerinda yang disebut universal cylindrical grinding attachment dalam jumlah yang memadai. Dengan alat ini maka dapat dilakukan proses penggerindaan silindris baik silindris dalam maupun silindris luar. Dan untuk menghemat biaya yang dikeluarkan, alat ini nantinya akan dipasang pada mesin bubut konvensional yang ada di jurusan PT mesin. Dengan adanya alat ini, diharapkan akan memperlancar proses perkuliahan praktik pemesinan gerinda, 
sehingga kompetensi yang diharapkan, dapat dikuasai secara maksimal oleh mahasiswa.

Permasalahan yang akan dijawab melalui penelitian ini ada dua. Permasalahan pertama adalah bagaimana rancangan mesin universal cylindrical grinding attachment. Dan yang kedua bagaimana kelayakan mesin universal cylindrical grinding attachment yang telah dikembangkan. Mesin Gerinda adalah salah satu mesin perkakas yang digunakan untuk mengasah/memotong benda kerja dengan tujuan tertentu. Prinsip kerja Mesin Gerinda adalah batu gerinda berputar bersentuhan dengan benda kerja sehingga terjadi pengikisan, penajaman, pengasahan, atau pemotongan. Bekerja dengan mesin gerinda prinsipnya sama dengan proses pemotongan benda kerja. Pisau atau alat potong gerinda adalah ribuan keping berbentuk pasir grinding yang melekat menjadi keping roda grinding. Proses penggerindaan dilakukan oleh keping roda gerinda yang berputar menggesek permukaan benda kerja.

Di Jurusan PT Mesin, proses pemesinan gerinda merupakan mata kuliah praktik berbobot 3 sks dan bersifat wajib lulus (revisi kurikulum PT. Mesin 2014). Mata kuliah ini membekali mahasiswa untuk memiliki pengetahuan, keterampilan, dan sikap kerja dalam mengoperasikan mesin gerinda universal, datar, dan silindris untuk menghasilkan berbagai jenis produk/komponen mesin dengan ketelitian dan kepresisian tinggi yang dikerjakan secara cermat, teliti, dan hatihati melalui perencanaan, pemilihan, dan penggunaan batu gerinda serta penerapan keselamatan kerja. Kemampuan akhir yang diharapkan dapat dikuasai oleh mahasiswa, setelah menempuh pembelajaran ini adalah mampu melakukan: (1) proses menggerinda berbagai bentuk alat potong dengan mesin gerinda universal; (2) proses menggerinda bentuk rata dan paralel; (3) proses menggerinda datar bentuk rata bersudut; (4) proses menggerinda bentuk silindris luar; (5) proses menggerinda bentuk silindris konis/taper; (6) proses menggerinda bentuk silindris internal
Sarana utama yang dibutuhkan dalam pembelajaran Pemesinan Gerinda adalah mesin gerinda. Beberapa macam tipe mesin gerinda yang ada dalam industri manufaktur antara lain: (1) mesin gerinda rata/ mesin gerinda permukaan (surface grinding machine); (2) mesin gerinda silindris (cylindrical grinding machine); (3) mesin gerinda untuk pengasahan alat potong (cutting tools grinding machine); (4) mesin gerinda untuk penggerindaan khusus (special grinding machine). (Widarto, 2008: 124). Sedangkan menurut Chapman (1981: 87), ada beragam macam tipe mesin gerinda silindris. Tipe mesin gerinda silindris menurut Chapman adalah (1) external cylindrical grinding machine; (2) Internal cylindrical grinding machine; (3) Universal cylindrical grinding machine; (4) Centreless cylindrical grinding machine. Masih menurut Chapman, universal cylindrical grinding machine adalah mesin gerinda silindris yang dapat melayani penggerindaan luar dan dalam sekaligus. Karena kondisi yang khusus ini, maka pada mesin ini dilengkapi dengan spindel yang dapat diatur.

Melihat dari proses penggerindaan terdapat beberapa jenis pengerjaan yang dilakukan. Taufik Rochim (1993), menjelaskan bahwa metode penggerindaan terdiri dari: (1) penggerindaan diameter luar yaitu penggerindaan memanjang diameter luar silindris diantara dua senter; (2) penggerindaan tegak lurus, digunakan pada penggerindaan silindris, konis dan bertingkat. Panjang bidang yang akan digerinda tidak melebihi tebal batu gerinda. Pada penggerindaan ini tidak ada gerakan memanjang; (3) penggerindaan bentuk, prinsipnya sama dengan penggerindaan tegak lurus, perbedaannya terletak pada bentuk batu gerinda yang dibentuk; (4) penggerindaan tirus luar yaitu penggerindaan ini dilakukan dengan cara menggeser meja bagian atas. Pergeseran maksimum adalah $12^{\circ}$. Penggerindaan dilakukan seperti penggerindaan silindris memanjang; (5) penggerindaan diameter dalam yaitu penggerindaan diameter dalam dengan benda kerja berputar. Prinsipnya sama dengan 
penggerindaan diameter luar. Diameter roda gerinda tidak boleh lebih besar dari 3/4 lubang diameter benda kerja. Spindel khusus dipasang pada kepala utama; (6) penggerindan tirus dalam yaitu penggerindaan dilakukan dengan cara menggeser meja sebesar sudut ketirusan Penggerindaan ini bisa dilakukan jika sudut ketirusan maksimal benda kerja kurang dari $12^{\circ}$; (7) penggerindaan dalam dengan benda kerja diam yaitu penggerindaan yang dilakukan jika ukuran dan bentuk benda kerja terlalu besar dan tidak dapat dicekam; (8) penggerindaan muka yaitu penggerindaan yang dilakukan untuk menggerinda muka (facing) sebuah silinder. Sebelum proses penggerindaan dimulai, batu gerinda harus ditruing $1^{\circ}$ ke arah pusat, meja diatur tepat $90^{\circ}$, sehingga akan menghasilkan permukaan yang tegak lurus terhadap sisi memanjang diameter benda kerja.

\section{METODE}

Penelitian tentang rancang bangun universal cylindrical grinding attachment ini termasuk dalam jenis Penelitian dan Pengembangan/ Reseach and Development (R\&D). Model R\&D yang digunakan adalah ADDIE Model (Dick \& Carey: 2010: 23), yang terdiri dari langkah-langkah: (1) Analysis, (2) Design, (3) Development, (4) Implementation dan (5) Evaluation. Sumber data/subjek dalam penelitian ini adalah 2 orang dosen pengampu mata kuliah Pemesinan Gerinda. Teknik pengumpulan data menggunakan teknik observasi dan alat pengumpul data menggunakan angket dan dokumentasi. Metode analisis data yang digunakan adalah deskriptif kuantitatif. Kelebihan dan kekuranagan mesin ini dijelaskan secara deskriptif, kemudian untuk penilaian kelayakan alat ini dilakukan secara kuantitatif.

\section{HASIL DAN PEMBAHASAN}

Penelitian ini dilaksanakan mengikuti prosedur/tahapan penelitian yang telah ditetapkan. Tahapan yang dilakukan meliputi analisis, desain, pengembangan, implementasi dan evaluasi. Hasil yang telah didapatkan, berdasarkan tahapan penelitian adalah sebagai berikut:

Tahap Analisis. Hasil dari tahapan ini adalah beberapa kebutuhan atau tuntutan yang harus dipenuhi dalam pengembangan mesin universal cylindrical grinding attachment: (a) kebutuhan akan fungsi mesin yaitu bisa menggerinda internal dan eksternal; (b) kekuatan mesin; (c) kemudahan dalam proses assembly komponen mesin; (d) kemudahan dalam proses setting pada mesin bubut; dan $€$ kinerja mesin.

Tahap Desain. Mesin universal cylindrical grinding attachment yang dikembangkan ini, dapat dipasang pada berbagai jenis mesin bubut manual, karena dilengkapi dengan dudukan yang dapat disetel menyesuaikan tool post mesin bubut yang akan digunakan, sebagaimana ditunjukkan pada Gambar 1.
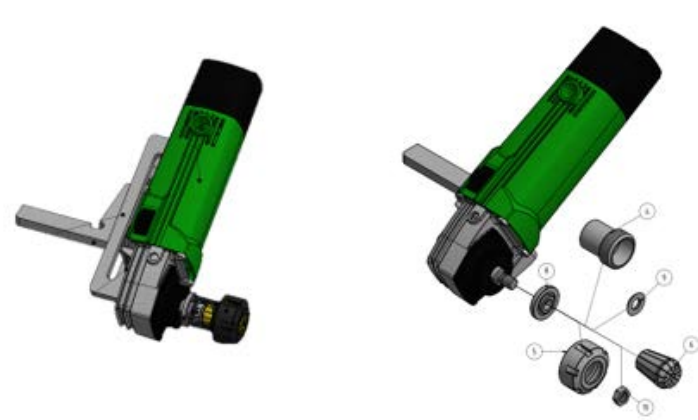

Gambar 1. Desain mesin universal cylindrical grinding attachment

Tahap Pengembangan. Sesuai rancangan desain mesin universal cylindrical grinding attachment tersebut, perlu dijelaskan bahwasannya mesin ini dikembangkan dengan memodifikasi mesin gerinda tangan yang sudah ada di pasaran. Hal ini dilakukan dengan beberapa pertimbangan, yaitu: (a) mesin gerinda tangan yang ada di pasaran, harganya terjangkau; dan (2) mesin gerinda tangan yang ada di pasaran memiliki berat yang tergolong ringan, sehingga memudahkan proses setting pemasangan pada mesin bubut. Sedangkan 
modifikasi yang dilakukan adalah pada prinsipnya menambah fungsi dari gerinda tangan tersebut, sehingga dapat digunakan untuk proses penggerindaan internal silindris. Hal itu dilakukan dengan membuat beberapa komponen/part sebagai pendukung dalam proses penggerindaan internal silindris, yaitu: tapper shaft, clamping nuts, slive, shank, nut, bottom holder, dan top holder Hasil pengembangan universal cylindrical grinding attachment dan cara pemasangan pada mesin bubut sebagaimana ditunjukkan pada Gambar 2.
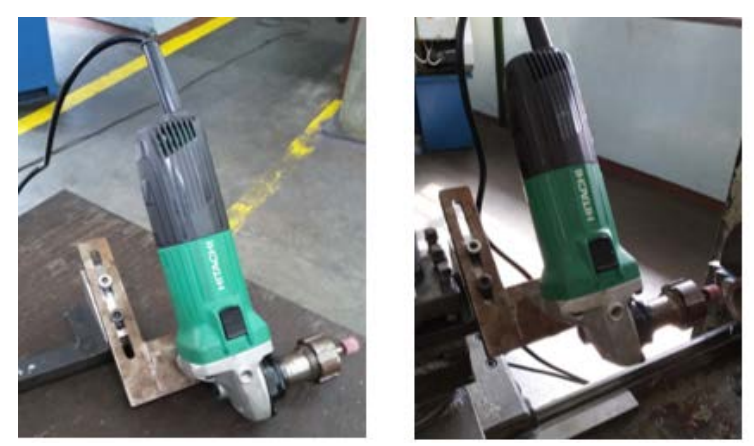

Gambar 2. Mesin universal cylindrical grinding attachment
Tahap Implementasi. Karena perkuliahan praktik Pemesinan Gerinda baru dilaksanakan pada semester genap, maka pada tahapan ini dimodifikasi menjadi proses uji coba pemakaian mesin, yang dilanjutkan proses validasi untuk diketahui kelayakannya dengan meminta penilaian dari beberapa dosen ahli, yang dalam hal ini adalah dosen pengampu mata kuliah Pemesinan Gerinda. Dokumentasi proses uji coba mesin universal cylindrical grinding attachment, sebagaimana ditunjukkan Gambar 3.

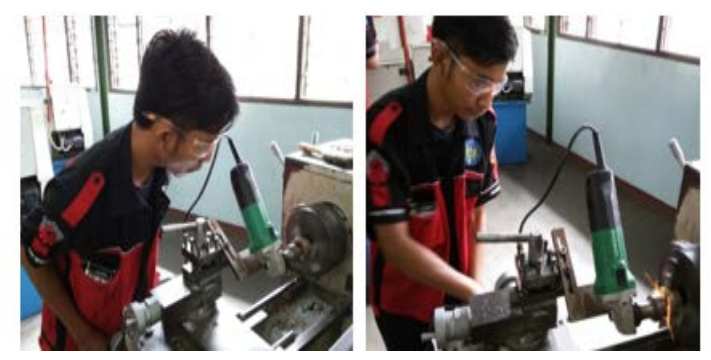

Gambar 3. Proses pengoperasian universal cylindrical grinding attachment

Tabel 1. Data hasil implementasi

\begin{tabular}{|c|c|c|c|c|c|}
\hline \multirow{2}{*}{ No. } & \multirow{2}{*}{ Aspek yang Diamati } & \multicolumn{2}{|c|}{ Validator } & \multirow{2}{*}{ Rerata } & \multirow{2}{*}{ Kategori } \\
\hline & & I & II & & \\
\hline 1 & Konstruksi universal grinding sudah baik & 4 & 4 & 4 & Sangat Setuju \\
\hline 2 & $\begin{array}{l}\text { Proses bongkar pasang universal grinding mudah } \\
\text { dilakukan. }\end{array}$ & 4 & 4 & 4 & Sangat Setuju \\
\hline 3 & Pengoperasian universal grinding mudah. & 4 & 4 & 4 & Sangat Setuju \\
\hline 4 & Universal grinding dapat berfungsi dengan baik. & 3 & 4 & 3.5 & Sangat Setuju \\
\hline 5 & $\begin{array}{l}\text { Universal grinding mampu menahan getaran selama } \\
\text { proses penggerindaan. }\end{array}$ & 3 & 4 & 3.5 & Sangat Setuju \\
\hline 6 & Universal grinding memiliki kekuatan yang baik. & 4 & 4 & 4 & Sangat Setuju \\
\hline 7 & $\begin{array}{l}\text { Hasil penggerindaan menggunakan universal grinding } \\
\text { baik. }\end{array}$ & 3 & 3 & 3 & Setuju \\
\hline \multirow[t]{2}{*}{8} & Secara umum, universal grinding sudah baik & 4 & 4 & 4 & Sangat Setuju \\
\hline & Rerata Keseluruhan Aspek & 3.625 & 3.875 & 3.75 & Sangat Setuju \\
\hline
\end{tabular}

Tahap Evaluasi. Berdasarkan hasil uji coba dan validasi, ada beberapa poin evaluasi yang masih menjadi kelemahan universal cylindrical grinding attachment yang telah dikembangkan. Poin tersebut adalah: (1) agar didapatkan hasil penggerindaan yang lebih baik, sebaiknya dipilih mesin gerinda tangan dengan putaran (rpm) yang lebih tinggi; (2) pemilihan jenis batu gerinda, sebaiknya disesuiakan dengan material bahan yang akan digerinda; (3) untuk memperkokoh penyambungan dudukan dan mesin gerinda 
tangan, sebaiknya ditambah menjadi 2 buah baut; dan (4) ntuk pengembangan lebih lanjut perlu didesain sebuah transmisi yang mampu menambah/mempercepat putaran (rpm) mesin.

Penelitian ini pada prinsipnya ingin mengatasi permasalahan yang ada di jurusan Pendidikan Teknik Mesin, terkait dengan minimnya sarana yang dimiliki khususnya peralatan dan mesin gerinda, sebagai sarana utama dalam mata kuliah proses pemesinan gerinda. Peneliti berusaha mengembangkan peralatan yang dibutuhkan tersebut, dengan pertimbangan utama adalah multi fungi, sederhana dalam hal konstruksi, murah dan mudah dalam pengoperasiannya. Salah satu ide yang muncul adalah pengembangan mesin universal universal cylindrical grinding attachment.

Mesin ini dirancang dengan memodifikasi mesin gerinda tangan dimana fungsi utamanya adalah sebagai gerinda silindris luar. Mesin ini dimodifikasi sedemikian rupa sehingga memiliki fungsi tambahan mampu digunakan untuk gerinda silindris dalam. Agar fungsi tambahan tersebut dapat terwujud, maka dalam pengembangan mesin ini, dilakukan pembuatan beberapa komponen, yaitu tapper shaft, clamping nuts, slive, shank, nut, bottom holder, dan top holder. Mesin universal cylindrical grinding attachment, dirancang dan dikembangkan untuk dapat dipasang di mesin bubut manual. Agar lebih simpel dalam pemakaian pada mesin bubut, mesin ini dibuatkan holder yang dapat disetel menyesuaikan tool post pada mesin bubut. Sehingga mesin universal cylindrical grinding attachment ini dapat dipasang pada berbagai jenis mesin bubut konvensional.

Untuk memperoleh data tentang kelayakan pemakaian mesin universal cylindrical grinding attachment ini, dilakukan uji coba pemakaian dan validasi oleh dua orang yang merupakan dosen pengajar matakuliah Pemesinan Gerinda. Berdasarkan hasil uji coba pemakaian, mesin ini mudah dioperasikan. Selain itu mesin ini mudah dalam penyetingan baik untuk penyetingan mesin itu sendiri maupun dalam pemasangan pada mesin bubut. Dari segi fungsi, tujuan dari pengembangan mesin ini telah tercapai, yaitu mampu digunakan untuk menggerinda silindris luar maupun silindris dalam. Berdasarkan proses validasi oleh dosen pengajar pemesinan gerinda, mesin ini memperoleh penilaian dari validator I sebesar 3,625 dan dari validator II sebesar 3,875. Sehingga bila diambil rerata penilaian oleh kedua validator tersebut didapatkan skor penilaian sebesar 3,75. Dari tabel kategori yang telah ditentukan, maka rerata skor penilaian tersebut termasuk dalam kategori Sangat Setuju, sehingga dapat disimpulkan bahwa mesin universal cylindrical grinding attachment ini layak digunakan.

Meskipun demikian, mesin universal cylindrical grinding attachment ini masih memiliki beberapa kendala, diantaranya jumlah baut pengikat antara holder dengan tool post mesin bubut hanya 1, sehingga sangat rawan mudah kendor. Selain itu, putaran mesin gerinda tangan yang digunakan sebesar 11.000 rpm, sedangkan putaran gerinda silindris yang dipersyaratkan sekitar 30.000 rpm. Beberapa kelemahan ini menjadi tantangan tersendiri bagi tim peneliti, untuk dapat menyempurnakan mesin yang dikembangkan ini. Untuk target kedepan, mesin ini akan dikembangkan lebih lanjut, khususnya dalam 2 hal, yaitu; untuk memperkokoh penyambungan dudukan dan mesin gerinda tangan, akan ditambah menjadi 2 buah baut, disamping itu untuk pengembangan lebih lanjut perlu didesain sebuah transmisi yang mampu menambah/mempercepat putaran (rpm) mesin hingga mencapai putaran 30.000 rpm sehingga hasil penggerindaan uyang dicapai lebih halus.

\section{SIMPULAN}

Berdasarkan hasil penelitian yang telah didapatkan, dapat ditarik beberapa kesimpulan. Rancangan mesin universal cylindrical 
grinding attachment pada mesin bubut manual dibuat dengan memodifikasi mesin gerinda tangan, sehingga fungsinya bertambah yaitu mampu digunakan untuk menggerinda internal silindris. Modifikasi yang dimaksud, yaitu dengan membuat beberapa komponen/part, yaitu: tapper shaft, clamping nuts, slive, shank, nut, bottom holder, dan top holder. Berdasarkan data penilaian/validasi terhadap kelayakan mesin universal cylindrical grinding attachment, terlihat bahwa rentang penilaian rerata keseluruhan aspek termasuk dalam kategori sangat setuju, sehingga dapat disimpulkan bahwa mesin ini layak untuk digunakan.

\section{DAFTAR RUJUKAN}

Dick \& Carey. (2010). ADDIE Model. diakses pada tanggal 1 Maret 2010 dari:http://www.learningtheories.com/ad die-model.html

Pemerintah Republik Indonesia. (2003). Undang-Undang No 20 Tahun 2003 tentang Sistem Pendidikan Nasional.
Pemerintah Republik Indonesia. (2005). Peraturan Pemerintah No 19 Tahun 2005 tentang Standar Nasional Pendidikan.

Pemerintah Republik Indonesia. (2005). Undang-Undang No 14 Tahun 2005 tentang Guru dan Dosen serta Penerapan Kurikulum 2013.

Pemerintah Republik Indonesia. (2017). Surat Keputusan Direktorat Jendral Pendidikan Dasar dan Menengah No 130 Tahun 2017 tentang Struktur Kurikulum Sekolah Menengah Kejuruan.

Taufiq Rochim. (1993). Teori dan teknologi Proses Permesinan. Jakarta: Higher Education Development Support Project.

Tim Penyusun. (2014). Revisi Kurikulum 2014 Program Studi Pendidikan Teknik Mesin (S1) dan Teknik Mesin (D3). Jurusan Pend. Teknik Mesin FT UNY.

W.A.J. Chapman. (1981). Senior Workshop Calculations. London: Edward Arnold (Publisher) LTD.

Widarto. (2008). Proses Pemesinan. Jakarta: DPSMK 